Témoigner

Getuigen
Témoigner. Entre histoire et mémoire

Revue pluridisciplinaire de la Fondation Auschwitz

125 | 2017

Histoire et mémoire de la persécution des

homosexuel-le's par les nazis

\title{
De totale onontkoombaarheid van de geschiedenis
}

Gesprek met de Belgische theatermaker Thomas Bellinck over de rol en betekenis van geschiedenis in zijn werk

Le caractère totalement inéluctable de l'histoire. Entretien avec le dramaturge belge Thomas Bellinck sur le rôle et l'importance de l'histoire dans son cuvre

\section{Jasper Delbecke}

\section{(2) OpenEdition}

\section{Journals}

Édition électronique

URL : https://journals.openedition.org/temoigner/6297

DOI : 10.4000/temoigner.6297

ISSN : 2506-6390

Traduction(s) :

Le caractère totalement inéluctable de l'histoire - URL : https://journals.openedition.org/temoigner/ $6315[\mathrm{fr}]$

\section{Éditeur :}

Éditions du Centre d'études et de documentation Mémoire d'Auschwitz, Éditions Kimé

Édition imprimée

Date de publication : 1 octobre 2017

Pagination : 50-59

ISBN : 978-2-930953-01-4

ISSN : 2031-4183

Référence électronique

Jasper Delbecke, «De totale onontkoombaarheid van de geschiedenis», Témoigner. Entre histoire et mémoire [Online], 125 | 2017, Online op 24 décembre 2021, geraadpleegd op 04 février 2022. URL: http://journals.openedition.org/temoigner/6297 ; DOI: https://doi.org/10.4000/temoigner.6297 
'Engagement is een vorm van reageren op de geschiedenis', zei Stéphane Hessel, filosoof, diplomaat en peetvader van de Indignados-beweging. Dat motto gaat ook op voor de Belgische theatermaker Thomas Bellinck. In de voorstellingen van theatergezelschap Steigeisen, dat hij samen met acteur Jeroen Vander Ven heeft opgericht, speelt geschiedenis steevast een centrale rol.

$\rightarrow$ Jasper Delbecke (UGent)

\section{DETOTALE ONONTKOOMBAARHEID VAN DE GESCHIEDENIS}

Gesprek met de Belgische theatermaker

Thomas Bellinck over de rol en betekenis van geschiedenis in zijn werk.

\section{Steigeisen, in de maalstroom
van de geschiedenis: van Fobbit tot Memento Park}

Fobbit (2009) vertelt het verhaal van Belgische soldaen in Afghanistan aan de hand van films, boeken, folders, ten in Afghanistan aan de hand van films, boeken, folders,
flyers, brieven en interviews met een oorlogsverslaggever een paracommando met een staat van dienst in Libano en een officier van de luchtcomponent die regelmatig werd ingezet in Afghanistan. Het doel is hier niet zozeer in tegenstelling tot het positivistische documentairethe ater, om de waarheid te achterhalen achter een (histo. Solly, Jrry and the 38 Gun (2010) vorm Sally, Jenry and the .38 Gun (2010) vormt niet zozeer een reconstructie van de moordpoging op Gerald Ford op 22 september 1975 in San Francisco, maar bevraagt de dunn Inc. (2011) is een powerping hc. (2011) is een powerpointvoorstelling over de zoek (2014) sat de ontreden figur van Maxinien de bare (2014) staa de omstreden figuur van Maximilien de Robespiere centraal, de visionaire staatsman en zelfverduizenden mensen onder de guillotine joeg.
In Memento Park (2015) legt Bellinck de mechanismen bloot die aan de basis liggen van de herdenkingsindustrie rond de Groote Oorlog. Belgiè - en vooral Vlaanderen - beleefde een hoogtepunt aan vieringen en herdenkerjoch verjaardag van de Eerste Wereldoorlog. Niet alleen op commercieel maar ook op polick vlak werd daar mun uit geslagen. Vlaams-nationalisten grepen de verjaardag in te enten je bazen en jongensonderiche Met de Jzerts vredesregio die dringend internationaal op de kaart geze moest word n. Wie herd, beshst ook om iets anders niet te herdenken', stelde Bellick nog naar aanloop van zijn stuk (Van der Speeten 2015, 6). Memento Park toont inderdade vershing a simultane herdenking van de Grote Oorlog en bevraag

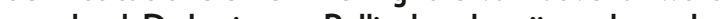
opgelegd. De basis voor Bellincks tekst zijn onder andere televisiereportages uit journaals, persmomenten van de oorlogsmusical 14-18, documenten van de toeristische tje in

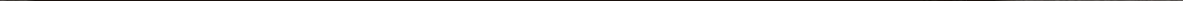


... Niet toevallig speelt deze voorselling methet format van de historscheriju prak ijk wa als amateurhistorici het verleden opnieuw tastbaar maken door veldslagen en middeleeuwse dorpen te reconstruren. Le Roy noemt deze chen vormen dichet "dod" verleden viade " willect willen maken' (Le Roy 2012, 13). Een videroek naar die mechanism

Volgens Le Roy laat Bellincks rea-

Volgens Le Roylaat Bellincks realistische enscenering van de geschiedenis toe om op ondubbelzinnige wijze de onthutsende ambiguiteit vij 'nu' wa 'ton' 's, 'theljkheid tegelijk, 'cu' en 'toen' 's 'theatra' 2016,25$)$ 'Concreet' en 'allegorsch' (2016, 25). werd werd omschreven als een theatergezelschap dat zich in de malstroom die de gerchis die omschijung anno 20160 niet meer volledig dekt.

Thomas Bellinck: Voor Billy, Sally, Jerry and the .38 Gun en Lethal In geldt die omschrijving zeker nog. In die voorsteningen hanteerden we geschiedenis echt als een instrument. Vanaf De Onkreukelbare daar de Franse Revolutie en de fiar de Transe Revolutie en de figuurvan Robespierre als een kapsek zrocess dis de processen ie tie te ven zijn aan ee (1) zoiets altijd. Hanna rends boek Revolutie ven blauwdruk was voor de Rus ce Franse hove de. Wat mij intrigeerde aandicanalyse is hetidee dat hun enen echter niet konden voorspellen was het ontstaan van de Arabische Lente, precies tijdens de creatie van prille begin van die revolutie. Pas toen we twee jar ater de voorstelling opnieuw speelden en de siturtie in Noord-Afrika volledig was ontspoord 'klopte' De Onkreulelbare voor ons. De voor telling was op die als-die-te-voorspellen-en-te-verwachten-is. Voor ons was het boeiend om vast te stellen dat je dingen maakt in én met de tijd, dat je voorstelling sterk onderhevis is aan de tijd.

\section{Geschiedenis als een gedeelde} verantwoordelijkheid:

Het spanningsveld tussen de kleinmenselijke verhalen en de grote Geschiedenissen, tussen de individuele en de intitutionele herinnering, komt sterk naar voren in $\mathrm{He}$ Mirakel van Almería, een driedelige documentaire waaran Bellinck samen met filmmaker Moon Blaisse momenteel de laatste hand aan legt. De streek rond het Spaanse westerse industrialisering en globalisering weerspiegelt. Wie even via Google Earth een blik werpt op de regio - en zeker op de steden El Ejido en Roquetas de Mar - ziet grom

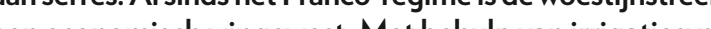
econ temen is het getran die bij Francokwamenvooralingale immigranten naar de streek o het zarewerk in de verzengende hitte uit te voeren. enorme impact op mens en milieu. Memento Park

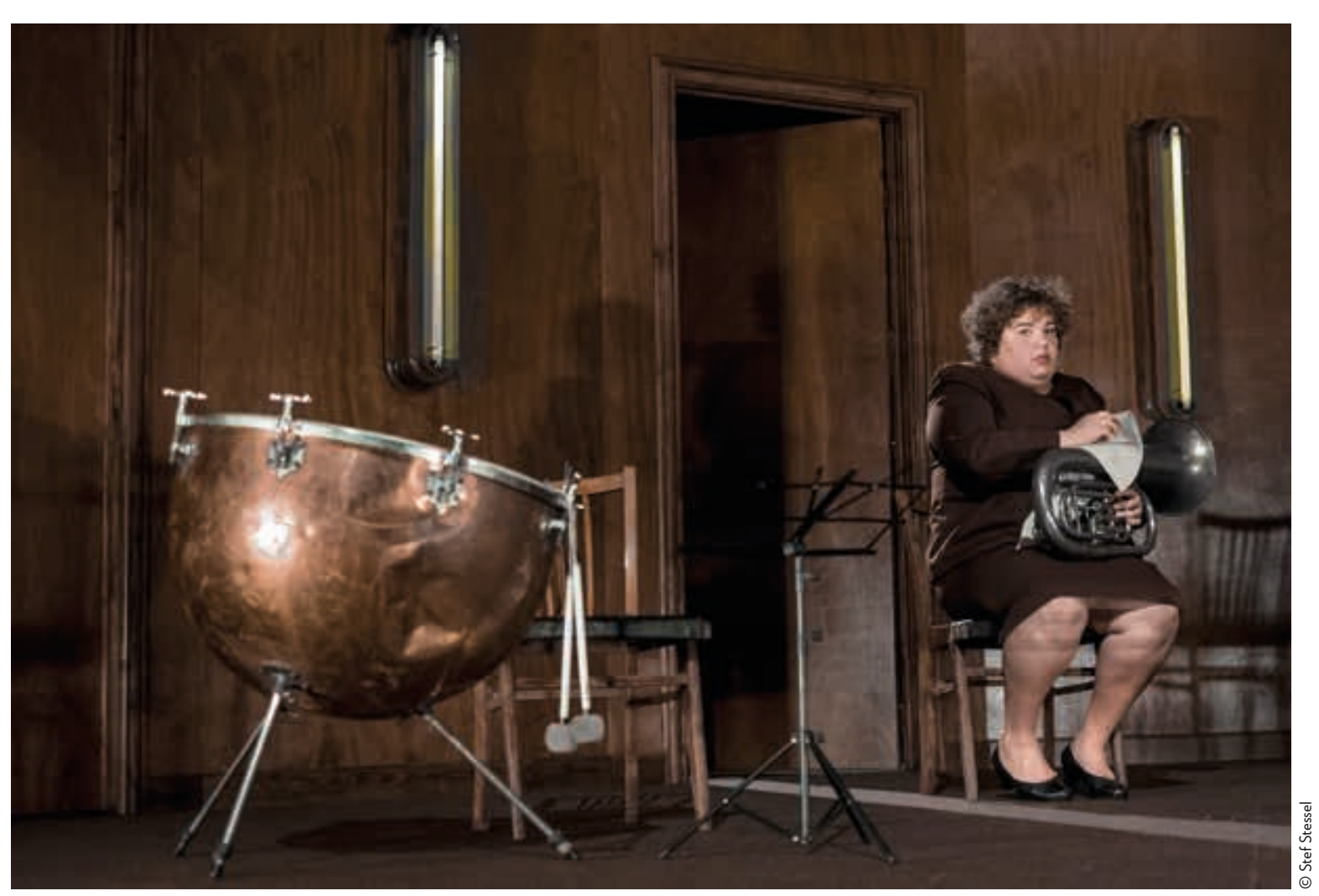
Almería vormt een microkosmos die tweehonderd jaar die bij ons in de warenhuizen te koop zijn. Na de val van Het Miraked van Almera toont niet alleen de uitwassen
De inzet van de voorstelling was dan ook een blauwdruk lat proces te laten zien: wat als je die zozeer om het historische verloop van die revij niet zor on maar om de theatrale denkoefening. Op welke wetten en praktische bezwaren stuiten alle revolutionairen de Franse, Russische en Iraans Revolutie. Wat we 
-. Bellinck: Het Mirakel van Almería is opgedeeld in drie delen: grofweg verleden, heden en toekomst. Telkens wilden we met eén specifieke bevolkingsgroe Wa Waar het in Memento Park draaide om institutionele herinnering, onderzoeken we hier hoe verschillende cer her 年, warbij we vertrekken van gesprekken net ouderen. Wat opviel, warende uiteenlopendegeturgenissenover hetbezoek van Franco aan Almera. Daarom besloten we over te gaan tot een soortre-enactnent: we huurden old me zoch nis et beject het geheel realistisch te maken, maar on levendige Onder de bej op te roepen en reacties uit te lokken. Onder de bas te zaten zowel notorire franquisten

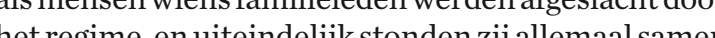
het regime, enciteindelijk stonden zij allemaal samen . van een acteur die Franco speelt.

De keuze voor de re-enactment van het Franco-be作 Killing Joshua Oppent Kiling. In die bekroonde documentaire laat Oppenheimer deledenvanvoritio doodsesk

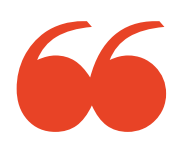

Het is niet voldoende om straffe uitspraken te doen en controversiële standpunten in te nemen. Theatermakers moeten ook nadenken over hun eigen positie. Ze mogen niet wegkijken van de complexiteit waar ze vaak zelf deel van uitmaken.

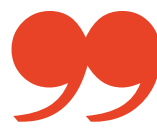

Bellinck: Wat ik problematisch vind aan The Act of Killing, en wat wij met Het Mirakel van Almería probevermijden, is het toewerken naar een catharsis. ppenheimer bouwt zijn relaas echt op naar dat ene moment waarop de daders tot inzicht komen. Zelijken lijue ondervin wanner ze hun eigen daden aan den lijve ondervinden, maar zoals ik het ervaren heb, is dit vooral het resultaatvan Oppenheiner's manipulatieve manier van monteren. De daders dragen vaak andere kleren, dus ik vermoed dat er is gefilmd op verschillende tijdstippen. De uiteindelijke documentaire i On die reden vind ik de film molistisch, e

Om die reden vind ik de film moralistisch, een willen trapen. willen trappen. In tegenstelling tot Oppenheimer outsiderspositie in Indonsie hebben wij als Europeaan boven boter op het hoofd wat de situatie in lijk lijk ook groenten en fruit uit de serres van Almería. zijn Blasse en ik zijn niet alloen de fllmakers, we zijn ook de consument en maken dus deel uit van he verhaal. Onze verhouding tot het materiaal waarmee gater gaat er ons niet om de mensen tot inzicht te brengen, breng amen metalle and reactoren een verhaal te brengen waar wij als maker (maar dat geldt ook voo De parlel met The Act of Kiltinaken.

De parallel met The Act of Killing zie je voora in de eerste aflevering van Het Mirakel van Almería (over het verleden). Net als Oppenheimer kiezen we bewust voor een eenzijdig perspectief, namelijk da van de eerste pioniers die naar de streek kwamen in het Franco-tijdperk. Degenen die vandaag mensen uitbuiten op het land, waren zelf ooit migrant, maa zijn dat bljkbaar een beetje vergeten. De tweede aflevering ('heden') gaat over de frictie die ontstaa tussen die pioniers en de nieuwe bevolkingsgroepen die werk komen zoeken in de streek. In de laatste aflevering stellen we vragen over de toekomst van Almeria. Met alle actoren hielden we een congres voor en over een regio die schijnbaar geen toekoms heeft. De natuurlike bronnen zijn door de jaren van massale landbouw uitgeput, het zoetwater is op waardoor er op dure ziveningstinstall wordt, en de groente- en fruitteelt verschuift stilaan naar Zuid-Afrka. Precies hier schuilt volgens mij het grootste verschil met The Act of Killing: wij zitten als gale im
De realiteit daar is zo complex dat wij onmogelijk, en in tegenstelling tot Oppenheimer, een morele stellin kunnen innemen. In Het Mirakel van Almeria gaat he netoris maar gedeelde verantwoordelijkheden zijn. Ten tijde van De Onkreukelbare was het werk van Bellinck en Steigeisen doorspekt met 'verwondering', 'passie' en revolutie. Het activistische pad van toen bewandelt Bellinck niet Heer. De woede is er nog steeds, maar die kanaliseert hij nu op andere manieren. Want gedurfde theater op.

Bellinck: Het is niet voldoende om straffe uitspraken te doen en controversiële standpunten in te nemen. te doen en controversiële standpunten in te nemen. positie Ze mogen niet wegkijken van de compig positie. Ze mogen net wa waar ze zelf vaak deel van uitmaken. Mijn activisme

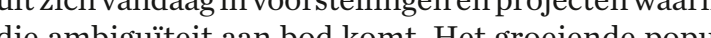
die ambiguiteit an bod komt. Het groeiende populisme bestrijd je niet door schuldigen aan te wijzen, (a) gedeeld verleden. Schuld kan je alleen maar dragen verantwoorde

Voor mij is dat de definitie van activisme: vertelingen creëren, in welke vorm dan ook, die dynam seren en engageren voor de toekomst. We zijn in ee cultuur verzeild geraakt waarin we onze eigen mislukking permanent ensceneren, op kleine en grote schaal. En telkens worden we bewust gemaakt van onze eigen schuld or die van een ander. andere pistes zijn om te bewandelen, alleen is er vaneagebrekaanverbeeld en mee vorm te geven.

\section{Over nostalgie, en over geschiedenis als claim op de toekomst: Domo de Eŭropa Historio en Ekzilo}

'Het verleden verkoopt beter dan de toekomst', stelde Andreas Huyssen in Present Pasts. Urban Palimpsests and the Politics of Memory (2003). Een giftige wolk van nostalgie baant zich gestaag een weg tot diep in de vezels da dor politi als wapen wo waarin de globalisering zijn grenzen heeft bereikt en de verliezers hun ongenoegen uiten. In haar boek The Future of Nostalgia vat Svetlana Boym het mooi samen: 'One nostalgic not for the past the way it was, but for the past the way it could have been.' (Boym 2001: 351) In Domo de Europa Historio en Ekzilo (letterlijk: Het Huis van de Europese Geschiedenis in Ballingschap, 2013) speelt Thoma (ij) Belling uit de toekomst blikt dat museum terug op de geschiedeusvand Eesale uiteenspat. De zalen en gangen zijn gevuld met prullaria: vernel to een verzameling ingelijste Europese regelgevingen en $\mathrm{d}$

Europese Unie uit de doeken doet.

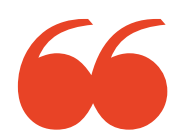

Domo de Eüropa biedt een nostalgische terugblik op het heden vanuit de toekomst en stimuleert daardoor een zeer ongewone en destabiliserende manier van herinneren. En het is net die afstand, die reflectie op ons eigen momentum, die verhelderend en verfrissend is.

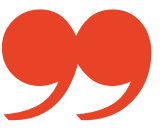

Bellinck: Nostalgie gebruik ik als theatraal midde et is een instrument en tegelijkertijd een kritiek op de manierwarop bijoor teld kut een kritiek op e manier waarop bijvoorbeeld musea nostalgie inzet. beeld daarvan. Dit partementaire bezoekerscentrum ertelt de geschiedenis van de Europese eenwording In wezen is het de wezen is het een propagandamuseum, midden in vertoont het Parlementarium veel gelijkenissen me het Museum van de Communtische Partijin China. 
$\cdots$ momentum te bevinden. De wereldorde die de laatste halve eeuw de spelregels heeft bepaald, wordt vandaag hertekend. Populisme, nationalisme en conservatisme

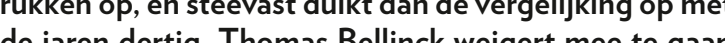
in die gedachte.

Bellinck: Het is de ziekte van onze tijd om terug te grijpen naar voorbije historische periodes om vervolgens hedendaagse tendensen te gaan verklaren. Een methode die volgens mij weinig bijdraagt tot het debat, en en zowel door de linker-als rechterzijde wordt gebeilond. Ik vind het een gevaarlijke reflex. Trouwens, als ikonze tijd al zou moetenvergelijken met een eerdere periode, dan zeker niet met de jaren dertig, maar met Het was een tijd van sterke globalisering en inter-

- Domo de Eŭropa Historio en Ekzilo (Huis van de Europese Geschiedenis in Ballingsschap)

\section{O}

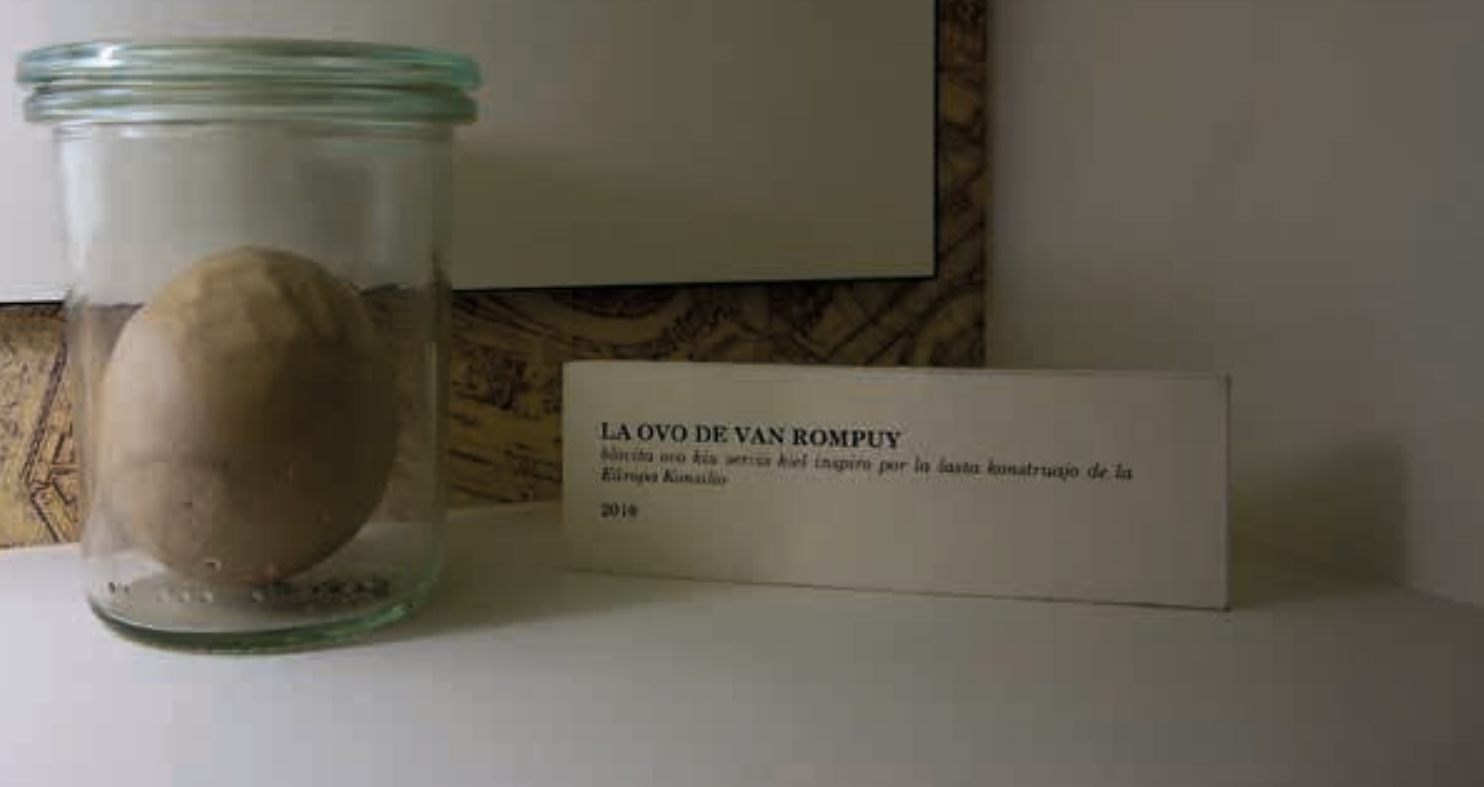

nationalisering waarbij economie en politiek in een stroomversnelling kwamen. Natiestaten begonnen zich te profileren en tegelijkertijd ontstond een soort van pan-Europese beweging. De beurscrash van 1873 ging gepaard met een economische implosie die overa ter wereld voelbaar was. Op datzelfde moment stroomden in Europa Ostjuden toe die de Russische pogrom in een dergelijke perio in jaren dertig. Ik heb het gevoel dat op dit noment de anter ophieuw we anders op het spelbord zullen kunnen nog elke kant op.

teeran Zweig pleegde kort voor het uitbreken va de Tweede Weresconzelfmoord nadat hij naar Bra hiliè was gellacht, ontredder over hoe 'zijn' Europ hewijst voor mij de totale onotkoom de eschiedenis. Jk weet wat het is om je als kosd aan gesche enijelection mens ben dan Zweig Ee der een con ist. (lacht)

Meer weten

$\Leftrightarrow$ In Getuigen 118 (september 2014) leest u een interview met Joshua Oppenheimer over Zijn documtaire The Act of Killing en $\rightarrow$ Bibliografie

$\rightarrow$ Svetlana Boym, The Future of Nostalgia, New York: Basic

$\diamond$ Grégoire Chamayou, Manhunts. A Philosophical History vertaald uit het Frans door Steven Randall, Princton \& Oxford: Princeton University Press, 2012.

$\diamond$ Evelyne Coussens, "'Wij worden voortdurend ingehaald door de tijd. Steigeisen zet zich schrap in de maalstroom van geschiedenis', Etcetera: Tijdschrift voor podiumkunsten 130, 2012 ,

$\diamond$ Jasper Delbecke. "Zou een heel klein beetje oorlog soms niet beter kunnen zinn": over de WO Therdenkingen, Thomas (n) Tijdschrift voor theater 33 (2), 2015, 57-82.

$\Delta$ T.J. Demos, The Migrant Image: The Art and Politics of Documentary during Glob

$\diamond$ Erika Fischer-Lichte, History of European Drama and Theatre

$\Delta$ Francis Fukuyama, The End of History and the Last Man, Free Press, 1992. $\Delta$ François Hartog, Regimes of Historicity. Presentism and
Experiences of Time [2003], vertaald uit het Frans door Saskia Brown, New York: Columbia University Press, 2015. $\Delta$ Andreas Huyssen, Present Pasts. Urban Palimpsests and the
Politics of Memory, Stanford: Stanford University Press, 2003. $\triangle$ Frederik Le Roy, Verknoopte tijd, verfrommelde geschiedenis.
een theaterwetenschappelijk en geschiedfilosofisch onderzoek naar een theaterwetenschappelijk en geschiedfilosofisch onderzoek naar theater en performance als politiek van de herinnering in het
en presentistisch historiciteitsregime, doctoraatsproefschrift,

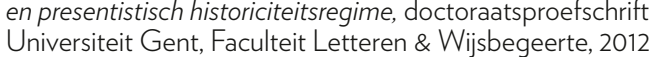

$\Delta$--, 'Realistische rituelen. De documentaire dubbels van Milo Rau en het International Institute of Political
Tijdschrift voor podiumkunsten 146, 2016, 20-25.

$\diamond$ Jacques Rancière, The Future of the Image [2007], vertaald ui het Frans door Gregory Elliott, Londen \& New York: Verso Books.

$\diamond$ Geert Van der Speeten, “"Ik wil alles op zijn kop kunnen zetten": Thomas Bellinck maakt "Men $\triangle$ Samuel Weber, Theatricality as Medium, New York: Fordham
University Press, 2004. 